\title{
A Combined Bio-Chemical Synthesis Route for 1-Octene Sheds Light on Rhamnolipid Structure
}

\author{
Till Tiso $^{1,+}{ }^{\mathbb{D}}$, Daniel F. Sauer ${ }^{2,+} \mathbb{D}$, Klaus Beckerle ${ }^{2}$, Christian C. Blesken ${ }^{1}$, Jun Okuda ${ }^{2}$ and \\ Lars M. Blank ${ }^{1, *}$ \\ 1 iAMB-Institute of Applied Microbiology, RWTH Aachen University, Worringerweg 1, D-52074 Aachen, \\ Germany; till.tiso@rwth-aachen.de (T.T.); carl.blesken@rwth-aachen.de (C.C.B.) \\ 2 Institute of Inorganic Chemistry, RWTH Aachen University, Landoltweg 1, D-52056 Aachen, Germany; \\ d.sauer@biotec.rwth-aachen.de (D.F.S.); klaus.beckerle@rwth-aachen.de (K.B.); \\ jun.okuda@ac.rwth-aachen.de (J.O.) \\ * Correspondence: lars.blank@rwth-aachen.de; Tel.: +49-241-80-26000 \\ + These authors contributed equally.
}

Received: 13 July 2020; Accepted: 31 July 2020; Published: 4 August 2020

check for updates

\begin{abstract}
Here we report a chemoenzymatic approach to synthesize 1-octene from carbohydrates via ethenolysis of rhamnolipids. Rhamnolipids synthesized by P. putida contain a double bond between carbon five and six, which is experimentally confirmed via olefin cross metathesis. Utilizing these lipids in the ethenolysis catalyzed by a Grubbs-Hoveyda-type catalyst selectively generates 1-octene and with good conversions. This study shows the potential of chemoenzymatic approaches to produce compounds for the chemical industry from renewable resources.
\end{abstract}

Keywords: ethenolysis; rhamnolipids; olefin metathesis; chemoenzymatic approach; renewables

\section{Introduction}

For a biobased economy, the renunciation of fossil resources as feedstock for the chemical industry is essential [1]. Modern biotechnology might produce building blocks for the chemical industry based on renewable resources [2,3]. To this end, biological processes have to be established for converting biomass to industrially useful intermediates. Microbial fermentations are also suited for the targeted synthesis of molecules from biomass for subsequent chemical conversion.

A promising organism for this application is Pseudomonas putida. P. putida is a Gram-negative soil bacterium that has been investigated extensively since the 1970s [4,5]. Genetic engineering efforts have led to the production of a broad palette of industrially relevant platform chemicals [6-9] with some industrial applications already established [10].

One class of molecules synthesized by P. putida on the laboratory scale are rhamnolipids [11]. Rhamnolipids are biosurfactants that can be utilized for a wide range of applications. Because of their amphiphilic characteristics they can act, for example, as emulsifying [12] and foaming [13] agents. Furthermore, they are biodegradable and therefore have a low impact on the environment [14].

Rhamnolipids are a diverse group of molecules with more than 60 reported congeners [15] and consist of one or two hydrophilic carbohydrate rhamnose and the hydrophobic moiety, composed of a monomer, dimer or trimer of esterified $\beta$-hydroxy fatty acids (Figure 1). If the fatty acids are 3-(3-hydroxyalkanoyloxy) alkanoates, the hydrophobic part is called in short HAA. Overall structural differences result from variations in the carbohydrate and in the hydrophobic moiety. The number of both the carbohydrate residues and the $\beta$-hydroxy fatty acids is usually either one or two, but up to three $\beta$-hydroxy fatty acids have been reported [16]. On the other hand, the number of carbon atoms in the $\beta$-hydroxy fatty acids can vary widely between six [17] and 24 [18], with most scientific papers 
reporting values between eight and 16 [15]. Interestingly, some congeners are reported to feature a unit of unsaturation [15]. However, the position of the double bond has not been determined so far.

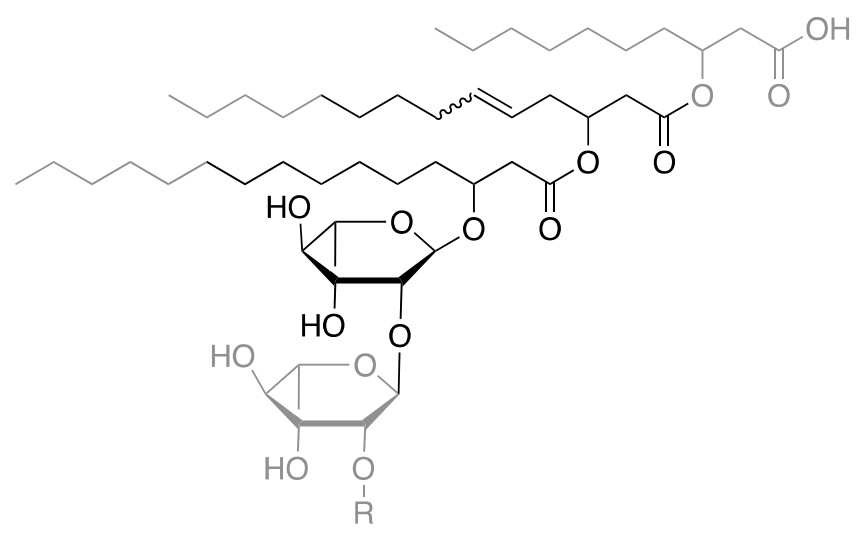

Figure 1. Structure of rhamnolipids. The hydrophobic moiety consists of an ester of two $\beta$-hydroxy fatty acids named hydroxyalkanoyloxy alkanoate (HAA). The chain lengths of these $\beta$-hydroxy fatty acids in this dimer can vary. One or two rhamnose molecules are bound by a glycosidic bond to the hydroxy group. The carbohydrate is the hydrophilic moiety of the molecule.

The rhamnolipid synthesis pathway involves two key enzymes. The acyltransferase RhlA linking two hydroxy fatty acids to yield the HAA and the rhamnosyltransferase RhlB attaching a rhamnose molecule to the HAA to form a mono-rhamnolipid (Scheme 1). The chain length is determined by the specificity of the RhlA [19], which is supplied with the complete fatty acid spectrum the host cell is capable of synthesizing via de novo fatty acid synthesis. It has recently been shown that exploiting the natural diversity of RhlAs from different species enables the host cell to synthesize HAAs of varying chain lengths [20].

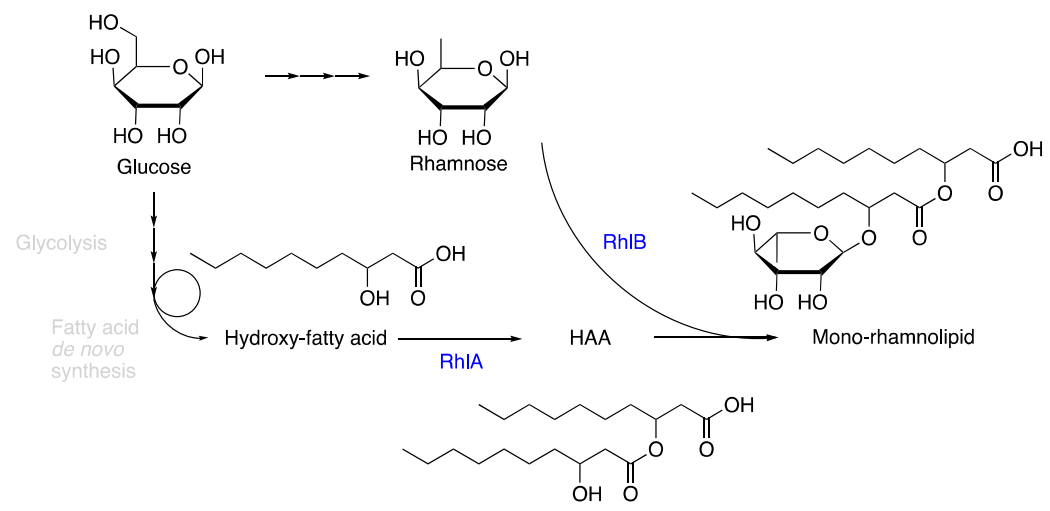

Scheme 1. Rhamnolipid synthesis pathway. RhlA—acyltransferase, RhlB—rhamnosyltransferase.

The olefin metathesis reaction is a powerful tool to convert $C=C$ double bonds via rearrangement with other olefins [21]. Ruthenium-based carbene catalysts (so-called Grubbs catalysts) in combination with modified Grubbs-Hoveyda-type catalysts allow transformation of such olefins with a broad variety of functional groups present [22]. Olefin metathesis offers synthesis pathways to convert biobased substrates such as oils and fatty acids into fine chemicals and fuel components, explaining the considerable interest in this reaction [23-40].

Beside other metal-based catalysts [41-44], the relatively high stability of the Grubbs-Hoveyda-type catalysts allows the combination of metal catalysis and proteins or enzymes in one pot in a concurrent or sequential fashion. Thereby, novel synthetic routes are investigated 
that enable the efficient synthesis of compounds starting from different resources such as renewables. The bioorthogonality of the olefin metathesis reaction does not interfere with the reaction or with cosubstrates of the enzymes. Nonetheless, compatibility challenges need to be overcome. Commonly, cell or media components inhibit metal catalysis $[42,43,45]$. Overcoming these challenges involves the utilization of compartmentalization strategies [42,46], utilization of biphasic systems,[47] generation of artificial metalloproteins capable of catalyzing the olefin metathesis reaction [48-52] or, if the enzyme allows, the utilization of cosolvents [53-55].

Ethenolysis utilizes ethylene as reaction partner and converts internal double bonds into terminal double bonds. The reaction is highly selective, reducing side product formation to a minimum. Furthermore, this reaction can be shifted to completeness by applying an excess of ethylene. After the reaction and simple removal of excess ethylene, the catalyst needs to be removed or quenched, because the reaction might equilibrate back by releasing ethylene in the cross-metathesis $(\mathrm{CM})$ reaction of terminal double bonds (Scheme 2).
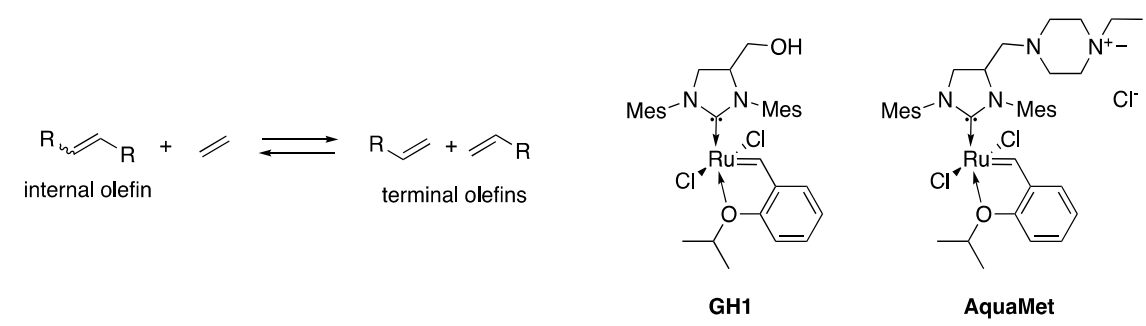

Scheme 2. Ethenoylsis reaction catalyzed by the Ru-carbene Grubbs-Hoveyda-type catalyst GH1 and AquaMet used in this study.

Ethenolysis is already industrially used for the conversion of various plant oils reaching scales of multiple kilotons per year [56]. However, further renewable resources (e.g., derived from lignocellulosic biomass) remain largely untouched due to the low activity in the conversion of electron-poor double bonds. Further challenges for the application of ethenolysis on biomass-derived substrates are the pool of functionalities (e.g., $-\mathrm{OH},-\mathrm{NH}_{2},-\mathrm{COOH}$, carbonyls) that are challenging for olefin metathesis catalysts, especially for water- and moisture-sensitive catalysts of the Schrock type on the basis of tungsten or molybdenum. The ruthenium-based metathesis catalysts (so-called Grubbs catalysts) are partially able to overcome this inactivation due to an increased stability towards protic substrates and functional groups [57]. Purification of substrates derived from biomass can be sophisticated and hence expensive. Therefore, catalysts that can tolerate a certain number of side-products are in favor for the conversion of biomass-derived substrates.

Nonetheless, ethenolysis of biomass-derived molecules gives access to terminal olefins from renewable resources. Today, one of the most significant processes to obtain terminal olefins is the Shell Higher Olefin Process (SHOP) with an annual production of more than one million tons [58] or via tetramerization of ethylene using chromium catalysts $[59,60]$. Olefins are valuable compounds, for example, in polymer chemistry [61] or as synthetic building blocks to be converted further as in the hydroformylation reaction [62].

We here present a two-step reaction route from carbohydrates to higher olefins. The first step includes a biological conversion of glucose to a fatty acid derivative using a whole-cell biocatalyst. The second step consists of the ethenolysis of unsaturated fatty acids catalyzed by the Grubbs-type catalysts applying ethylene. As catalyst for this transformation, we chose the relatively air- and water-stable Grubbs-Hoveyda-type catalysts GH1 and AquaMet (Scheme 2).

\section{Results and Discussion}

The here established bio-/chemical route to olefins via a biological intermediate consists of (1) the microbial synthesis of HAAs/rhamnolipids in conventional shake flasks and (2) the subsequent ethenolysis in chemical reactors. 


\subsection{Synthesis of the Biological Intermediate}

Recombinant Pseudomonas strains were previously engineered for the synthesis of HAAs and rhamnolipids [9]. To this end, the genes rhlAB and rhlA for the synthesis of rhamnolipids and HAAs, respectively were derived from P. aeruginosa. The resulting strains P. putida KT2440 pPS05 (rhamnolipid synthesis) and P. taiwanensis VLB120 pSB01 (HAA synthesis) were cultivated in Fernbach flasks using lysogeny broth (LB) supplemented with D-glucose and the respective antibiotics. By discrete feeding of glucose constant surfactant synthesis was achieved resulting in a titer of $0.66 \mathrm{~g} \mathrm{~L}^{-1} \mathrm{HAA}$ and $0.95 \mathrm{~g}$ $\mathrm{L}^{-1}$ rhamnolipids, after 3 and 4.5 days, respectively (Figure 2).
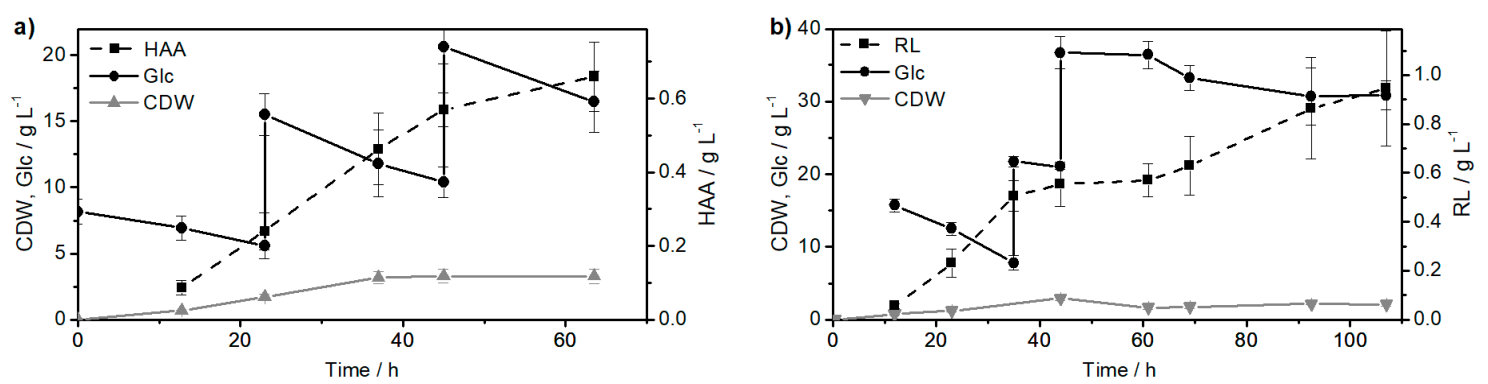

Figure 2. Synthesis of the biological intermediate. (a) HAA synthesis by a recombinant $P$. taiwanensis strain with pulsed addition of glucose. (b) Rhamnolipid synthesis by a recombinant $P$. putida strain. The grey curves (triangles) show the course of biosurfactant (HAA and rhamnolipid) synthesis, while the black line (circles) represents glucose concentrations. The dashed line (squares) shows the cell dry weight $(\mathrm{CDW})$.

The resulting congener mixture of HAAs contained $70 \%(\mathrm{w} / \mathrm{w}) \mathrm{C}_{10}-\mathrm{C}_{10}$, a dimer of hydroxydecanoate. $10 \%$ were $C_{10}-C_{12}$, while the shorter $C_{8}-C_{10}$ congener made up $8 \%$. About $10 \%$ were the congener $\mathrm{C}_{10}-\mathrm{C}_{12: 1}$ with a double bond containing hydroxy fatty acid. The congener composition of the rhamnolipids was similar with: $68 \% \mathrm{C}_{10}-\mathrm{C}_{10}, 14 \% \mathrm{C}_{10}-\mathrm{C}_{12: 1}, 13 \% \mathrm{C}_{10}-\mathrm{C}_{12}$, and $5 \% \mathrm{C}_{8}-\mathrm{C}_{10}$ (Figure 3).

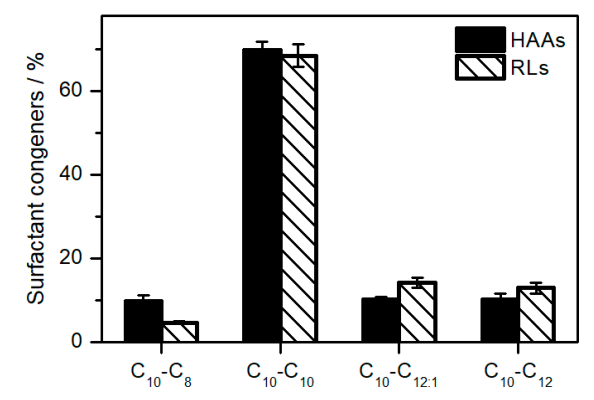

Figure 3. HAA and RL congeners formed during cultivation. The values are derived from three biological replicates.

In the metathesis reaction, only the congener carrying the unsaturation is accessible. For that reason, two purification steps were carried out; via an adsorption/desorption process, hydrophilic medium components and metabolites were removed. After evaporation of the eluent (ethanol), the highly concentrated surfactant solutions were subjected to chromatographic separation using a preparative HPLC system. Both adsorption and desorption showed recoveries above $99 \%$.

While in this study, glucose has been used for the synthesis of the intermediate molecules, recent studies show that the usage of components of lignocellulosic biomass is an option (e.g., xylose [63]). This would increase the sustainability of the here proposed approach. 


\subsection{Ethenolysis of $H A A / R h a m n o l i p i d s$}

First, a sample of HAA was characterized by ${ }^{1} \mathrm{H}$ NMR spectroscopy to determine the amount of double bonds in the molecule. Based on the generalized structure of the HAA (Figure 1), an ester of two 3-hydroxy-alcanoic acids, the number of double bonds was determined to be one double bond per HAA molecule (Figure 4).

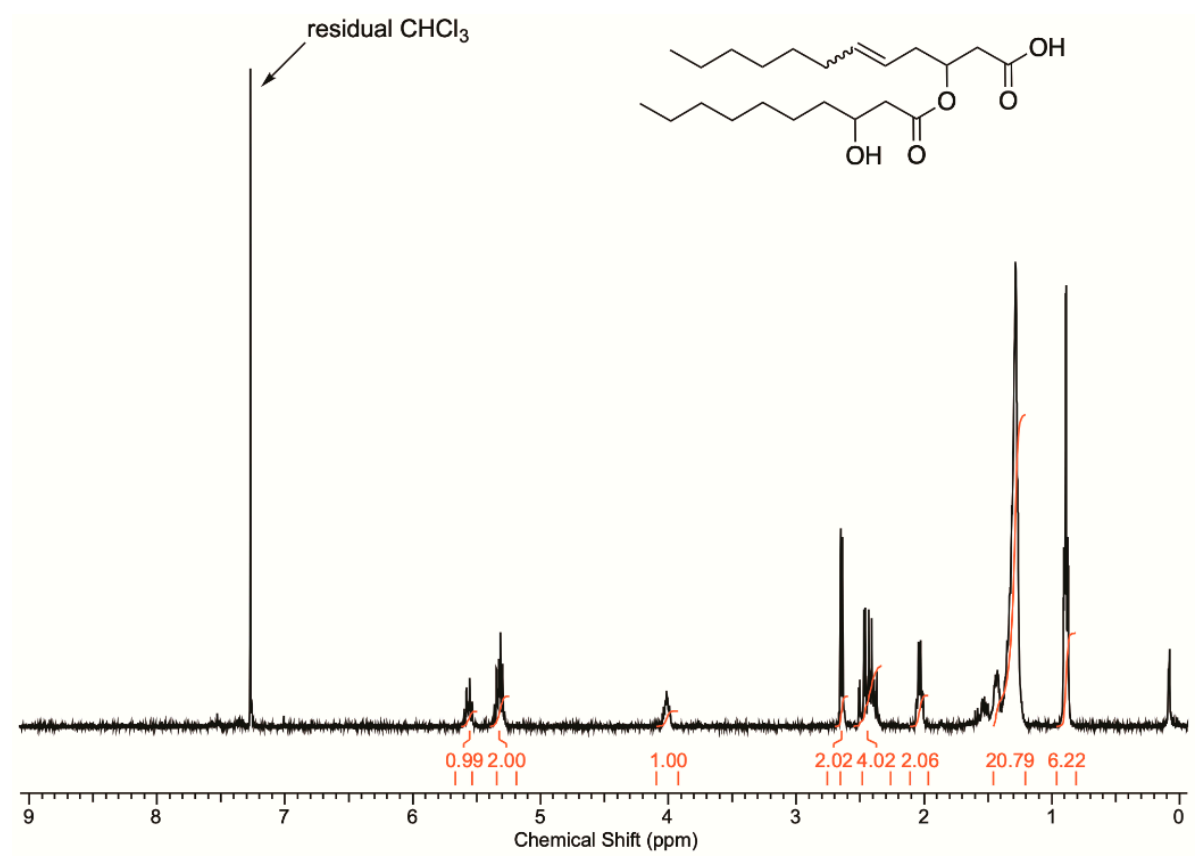

Figure 4. ${ }^{1} \mathrm{H}-\mathrm{NMR}\left(400 \mathrm{MHz}, 23{ }^{\circ} \mathrm{C}, \mathrm{CDCl}_{3}\right)$ spectrum of the proposed HAA.

For the ethenolysis reaction, a Grubbs-Hoveyda-type catalyst containing an alcohol group (GH1) was chosen. The ethenolysis reaction of HAA was performed in a Parr reactor (Figure 5).

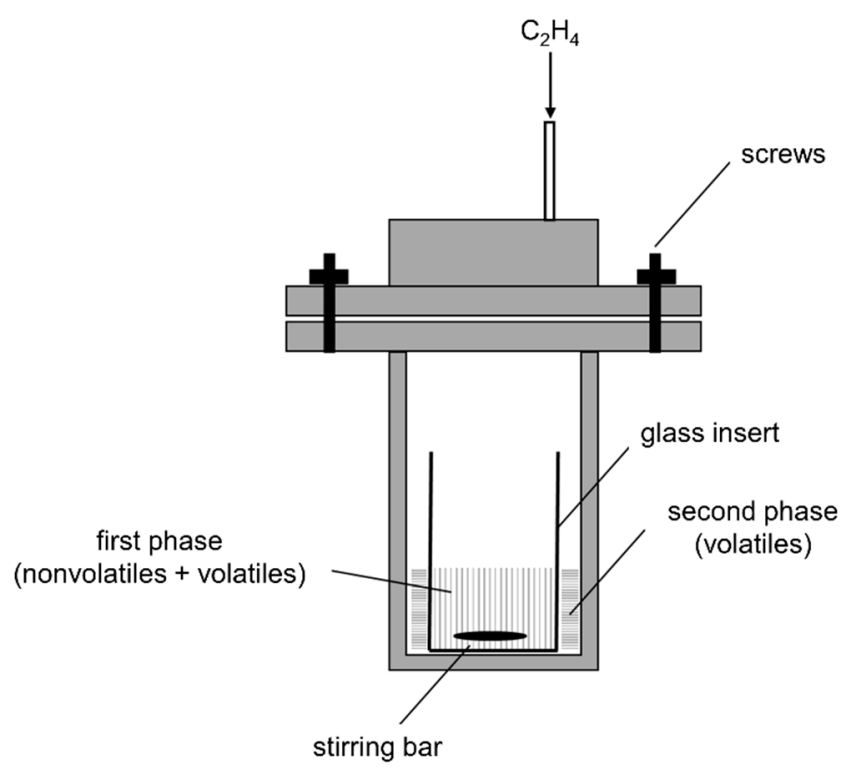

Figure 5. Picture of the Parr reactor used for initial studies.

HAA was converted under mild conditions (Scheme 3). NMR-spectroscopic analysis of the reaction mixture was difficult as several similar species were present. This mixture comprised the two 
ethenolysis products owning now terminal double bonds as well as the cleaved styrene derivative after initiation of the metathesis reaction. Furthermore, a cross-metathesis reaction of the reaction partners after the release of ethylene could not be excluded, even though the catalyst was quenched with ethoxyethene. The liquid phase outside of the glass insert, which formed during the reaction, contained only volatile products and solvent. The products were identified by their signal patterns and integration in the ${ }^{1} \mathrm{H}$ NMR spectra. For further analysis an authentic sample was analyzed via GC MS. Apart from the styrene derivative, 1-isopropoxy-2-vinylbenzene, which formed from the precatalyst in the initiation step with ethylene, 1-octene was found exclusively, which was also confirmed by GC MS (Figure S1). Integration of the signals showed the ratio of both components to be 4:1 (1-octene: 1-isopropoxy-2-vinylbenzene), while it was found to be close to 3:1 in the phase inside the glass insert. This implies an overall conversion of HAAs of around $50 \%$. A considerable margin of error should be taken into account for the small reaction size and the big volume within the reactor. Furthermore, a loss of product due to evaporation during workup should be considered as well as further cross-metathesis reactions might occur after ethylene is released from the autoclave.

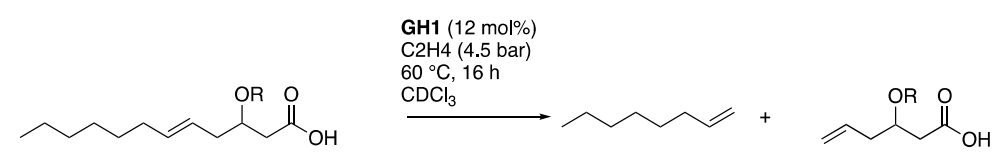

Scheme 3. Ethenolysis of HAA yielding 1-octene.

Encouraged by these results obtained for the conversion of HAA, we targeted direct conversion of the rhamnolipid. Applying ethenolysis directly to this metabolite would facilitate the process and reduce time and costs for the purification. Since rhamnolipids are water soluble, we performed ethenolysis in an aqueous environment utilizing the partially water-soluble olefin metathesis catalyst AquaMet under acidic conditions (favorable for the olefin-metathesis reaction in aqueous solutions) [64]. Following the conversion of the rhamnolipid, the reaction was performed in an NMR tube pressurized with 4 bar of ethylene in a 1:1 mixture of $\mathrm{D}_{2} \mathrm{O}$ and THF- $d_{8}$. The reaction was monitored by ${ }^{1} \mathrm{H}$ NMR spectroscopy at room temperature (Figure 6).

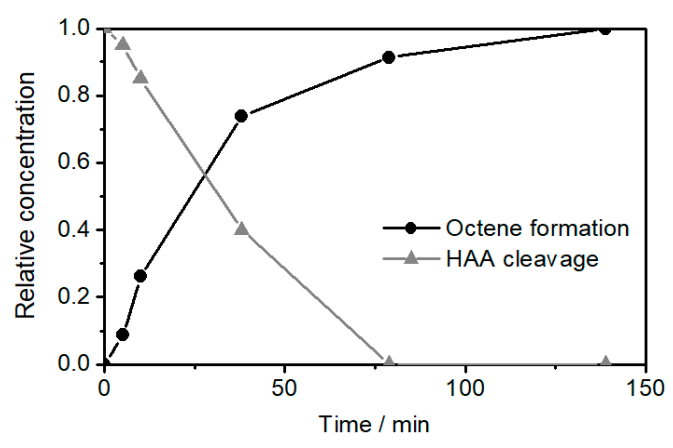

Figure 6. Time-dependent ethenolysis of the HAA part within the rhamnolipid and corresponding formation of 1-octene followed by ${ }^{1} \mathrm{H}-\mathrm{NMR}$ spectroscopy at $23{ }^{\circ} \mathrm{C}$.

Under these conditions, conversion of the rhamnolipid was complete within 80 min corresponding to quantitative conversion of the substrate. Noteworthy, due to overlapping signals of the mixtures of products during the conversion of the rhamnolipid, the end of octene formation was observed after $130 \mathrm{~min}$. Subsequent GC MS analysis of diethyl ether extracts of the reaction mixture confirmed the presence of 1-octene as the only volatile product. This result shows the feasibility of our approach to directly convert metabolites into valuable compounds by the chemoenzymatic approach. 


\subsection{Elucidation of Rhamnolipid Structures}

Ethenolysis of the rhamnolipid Rha- $\mathrm{C}_{10}-\mathrm{C}_{12: 1}$ congener and HPLC/NMR/GC MS analyses allowed us to locate the position of the unsaturated $\mathrm{C}=\mathrm{C}$ double bond. The occurrence of 1-octene in the product spectrum after ethenolysis indicated that the double bond was situated in the dodecenoic acid part. It has been shown in E. coli, that the 3-hydroxyacyl-ACP dehydratase (FabA) isomerizes the intermediate from fatty acid de novo synthesis trans-2-decenoyl-ACP to cis-3-decenoyl-ACP. This enzyme is very specific for the $C_{10}$ substrate and thus represents a branching point in fatty acid de novo synthesis. Elongation of the trans-2-decenoyl-ACP leads to saturated fatty acids while cis-3-decenoyl-ACP elongation yields mono-unsaturated fatty acids [65]. These findings fit our observation. With all information in hand, the HAA structure depicted in Figure 7 was derived.

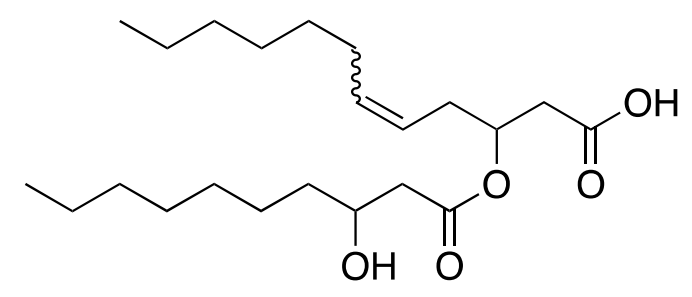

Figure 7. Proposed structure of the HAA molecule.

The commonly used method for rhamnolipid structure elucidation is mass spectrometry analysis. This technique however does not assist with determining the position of the double bond $[20,66]$. The results achieved here matched earlier observations, in which it was suggested that the double bond was located $\delta$ to the carboxylic acid forming a 5-enoic acid $[67,68]$. Further support was indicated by Behrens et al., who found the unsaturation in the dodecenoic acid moiety $[66,69]$.

This finding suggests that the incorporation of an unsaturation occurs in the fatty acid de novo synthesis during chain elongation. Since the RhlA here used is specifically incorporating $C_{10}$ fatty acids into the HAA molecule, a side activity for $\mathrm{C}_{8}$ and $\mathrm{C}_{12}$ fatty acids exists. As can be assumed from the spectrum of the produced HAAs, RhlA does not distinguish between saturated and mono-unsaturated fatty acids since the share of $C_{10}-C_{12}$ and $C_{10}-C_{12: 1}$ is roughly the same (Figure 2). The branching of the saturated and unsaturated fatty acid synthesis pathways usually occurs at the dehydration of $\beta$-hydroxydecanoyl-ACP to form trans-2-decenoyl-ACP [70]. This can also be seen here, as the $C_{10}$ fatty acids are saturated. This hypothesis is also supported by recent data from Germer et al. [20]. They utilized RhlA variants from different genetic backgrounds featuring specificities for fatty acids with higher chain lengths. Following this hypothesis, the share of unsaturation should increase with increasing chain lengths. Indeed, experimental data suggest the existence of such a correlation (Figure 8), supporting the theory that unsaturation occurs during fatty acid de novo synthesis after the fatty acids have reached a chain length of ten carbon atoms. Furthermore, the results from this study underline the ambiguity RhlA features, regarding double bonds.

A challenge that remains is the low percentage (10-14\%) of rhamnolipids and HAAs that have unsaturated double bonds. In order to increase the synthetic utility of the biochemical synthesis route for 1-octene, tools as metabolite engineering will help in increasing the share of unsaturated fatty acids. 


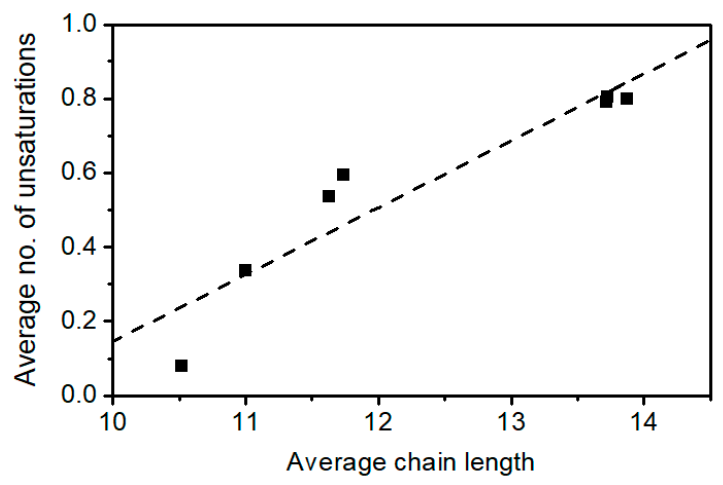

Figure 8. Correlation of chain length and unsaturation in HAA synthesis using RhlA variants from different genetic backgrounds. Data taken from Germer et al. [20].

\section{Experimental Section}

\subsection{Strains and Cultivation Conditions}

The used bacteria strains Pseudomonas putida KT2440 [71], Pseudomonas taiwanensis VLB120 [72] (formerly known as Pseudomonas species strain VLB120 [73]) were routinely cultivated in LB-media $(10 \mathrm{~g} / \mathrm{L}$ tryptone, $5 \mathrm{~g} / \mathrm{L}$ yeast extract, $10 \mathrm{~g} / \mathrm{L} \mathrm{NaCl})[74]$ at $30^{\circ} \mathrm{C}$. Cells containing the derivatives of vector pSEVA241 [75] were selected by adding kanamycin with a concentration of $50 \mu \mathrm{g} / \mathrm{mL}$ for recombinant E. coli and Pseudomonas, while for vectors based on pBBR1 [76] $20 \mu \mathrm{g} / \mathrm{mL}$ tetracycline was added. HAA production in Pseudomonas was carried out in LB-medium with additional $10 \mathrm{~g} / \mathrm{L}$ glucose and $50 \mu \mathrm{g} / \mathrm{mL}$ kanamycin. The shake flasks were incubated at $30{ }^{\circ} \mathrm{C}$ at a shaker speed of $80 \mathrm{rpm}$ (G25 Incubator shaker (New Brunswick Scientific Co. Inc., Enfield, USA) throw of $100 \mathrm{~mm}$ ) in $1.8 \mathrm{~L}$ Fernbach flasks with $500 \mathrm{~mL}$ of culture volume.

Vector pSB01 was constructed for $\mathrm{C}_{10}$-HAA production. It was created using pSEVA241 as backbone carrying the kanamycin resistance gene and pRO1600/ColE1 ori. Using PCR with forward (5'-ATCCAGGGTACCAGCTCTTG- $\left.3^{\prime}\right)$ and reverse (5'-CTGCATGCCTAGGCTTGTCAAGGAAAGG-3') primers rhlA originating from $P$. aeruginosa PA01 was amplified from a prior created plasmid (for rhamnolipid synthesis) and put under the control of a synthetic promoter called SynPro8. Using the endonucleases KpnI and SphI the vector as well as the PCR product were cut and the linear fragments were ligated. The ligated vector was then transformed into E. coli DH5 $\alpha$. For HAA production, the vector was subsequently transformed into P. taiwanensis VLB120.

\subsection{Purification}

The $500 \mathrm{~mL}$ culture broth was mixed with $250 \mathrm{~mL}$ acetonitrile for sterilization and protein precipitation. After acetonitrile evaporation, the suspension was centrifuged for $30 \mathrm{~min}$ at $8000 \mathrm{rpm}$ (Sorvall RC 5B PLUS, Thermo Fisher Scientific Inc., Waltham, MA, USA).

For adsorption, the supernatant was mixed with $3 \mathrm{~g}$ of silica adsorbent AA12SA5 (YMC Europe $\mathrm{GmbH}$, Dinslaken, Germany) for $1 \mathrm{~h}$ on a magnetic stirrer at $500 \mathrm{rpm}$. To separate liquid and adsorbent, the suspension was centrifuged at $8000 \mathrm{rpm}$ for $1 \mathrm{~h}$. Subsequently, the supernatant was discarded and the adsorbent was transferred into $50 \mathrm{~mL}$ ethanol and stirred for $1 \mathrm{~h}$ at $500 \mathrm{rpm}$ on a magnetic stirrer for desorption. After a following centrifugation at $5000 \mathrm{rpm}$ for $10 \mathrm{~min}$ (Heraeus Megafuge 16R from Thermo Fisher Scientific Inc., Waltham, MA, USA), the supernatant was separated and the ethanol evaporated until the volume was reduced to $10 \mathrm{~mL}$.

For the chromatographic separation, a preparative HPLC system consisting of the AZURA pump P6.1L and the AZURA autosampler 3950 (both Knauer GmbH, Berlin, Germany) connected to the SEDEX 58 LT-ELSD detector (SEDERE, Olivet, France) and the fraction collector Foxy R1 (Teledyne 
ISCO Lincoln, USA) using a VP250/21 NUCLEODUR C18 HTec column (Macherey-Nagel GmbH \& Co. KG, Düren, Germany) was employed. The flow rate was set to $10 \mathrm{~mL} / \mathrm{min}$ and $3 \mathrm{~mL}$ sample were injected for every run. As eluent, acetonitrile and ultrapure water supplied with $0.2 \%(\mathrm{v} / \mathrm{v})$ formic acid were used. For rhamnolipid separation, the gradient was linearly increased from $70 \%$ to $76 \%$ between 5 and $10 \mathrm{~min}$, from $76 \%$ to $80 \%$ between 10 and $25 \mathrm{~min}$, and to $100 \%$ until $35 \mathrm{~min}$. It was decreased back to $70 \%$ between 45 and $50 \mathrm{~min}$. The Rha- $\mathrm{C}_{10}-\mathrm{C}_{12: 1}$ congener was separated between 34.5 and $37 \mathrm{~min}$. For HAA samples, the acetonitrile concentration was linearly increased from $70 \%$ to $80 \%$ between 5 and $35 \mathrm{~min}$, and to $100 \%$ until $37 \mathrm{~min}$. It was decreased back to $70 \%$ from 42 to $52 \mathrm{~min}$. The measurement was terminated after $60 \mathrm{~min}$. The HAA $C_{10}-C_{12: 1}$ congener was separated between 45 and $48 \mathrm{~min}$.

As a final step, the solutions of the separated congeners were evaporated to remove the acetonitrile and water.

\subsection{Analytical Procedures}

\subsubsection{HPLC for Biosurfactant Quantification}

The rhamnolipid and HAA concentrations were characterized by reversed phase high performance liquid chromatography (RP-HPLC). As main column the model NUCLEODUR C18 Gravity of Macherey-Nagel GmbH \& Co. KG (Düren, Germany) was used (dimensions: $150 \times 4.6 \mathrm{~mm}$; particle size: $3 \mu \mathrm{m}$ ). The HPLC system Ultimate 3000 from Dionex Corporation (Sunnyvale, CA, USA) was connected to the Corona-charged aerosol detection (CAD) detector (Dionex Corporation, Sunnyvale, CA, USA). The flow rate was set to $1 \mathrm{~mL} / \mathrm{min}$ and the column oven temperature was set at $40{ }^{\circ} \mathrm{C}$. A portion of $5 \mu \mathrm{L}$ of the sample was injected. Acetonitrile and millipore water supplied with $0.2 \%$ $(\mathrm{v} / \mathrm{v})$ formic acid were used as eluent. The acetonitrile concentration was linearly increased from $70 \%$ to $100 \%$ between 1 and 9 min and it was linearly decreased from $100 \%$ to $70 \%$ between minute 11 and minute 12. One measurement was terminated after $15 \mathrm{~min}$. The rhamnolipid concentration of P. putida cultures was measured after 3 days of cultivation. A portion of $1 \mathrm{~mL}$ of the suspension was centrifuged for $5 \mathrm{~min}$ at 13,400 rpm. Then $500 \mu \mathrm{L}$ of the supernatant were subsequently mixed with $500 \mu \mathrm{L}$ of acetonitrile and centrifuged for $5 \mathrm{~min}$ at $13.400 \mathrm{rpm}$. To measure the samples, $150 \mu \mathrm{L}$ of the supernatant was filtered and pipetted into HPLC vials and measured.

\subsubsection{NMR Spectroscopy and GC MS Analysis}

NMR spectra were recorded on a Bruker Avance II 400 or Bruker Avance III HD 400 at ambient temperature. Chemical shifts were reported referenced to the residual NMR-solvent signal [77].

GC MS analysis was performed on a Shimadzu GCMS-QP 2010 Plus equipped with a $30 \mathrm{~m}$ FS-Supreme-5ms column from CS-Chromatographie Service GmbH. Helium 5.0 was used as carrier gas.

\subsection{Ethenolysis in a Parr Autoclave}

In a glass insert for a $22 \mathrm{~mL}$ Parr autoclave, $9 \mathrm{mg}(25 \mu \mathrm{mol})$ of the substrate were dissolved in $2 \mathrm{~mL}$ $\mathrm{CDCl}_{3}$ (or $\mathrm{CD}_{2} \mathrm{Cl}_{2}$ ) along with $2 \mathrm{mg}$ of the Grubbs-Hoveyda catalyst GH1 (synthesized as previously reported [78]) and the insert was equipped with a magnetic stirring bar. The glass vial was inserted and the autoclave was tightly closed. The autoclave was pressurized with ethylene (Ethylene 3.5, Gerling Holz\&Co, Hamburg, Germany) to 4.5 bar static pressure and put into an oil bath at $60^{\circ} \mathrm{C}\left(40^{\circ} \mathrm{C}\right.$ in case of $\mathrm{CD}_{2} \mathrm{Cl}_{2}$ ) and stirred. After $16 \mathrm{~h}$ the autoclave was cooled to ambient temperature and pressure was released. The two liquid phases (inside and outside of the glass insert) were separately analyzed by ${ }^{1} \mathrm{H}$ NMR spectroscopy. The liquid phase containing volatile products was analyzed by GC MS afterwards.

\subsection{Ethenolysis in High-Pressure Norell NMR Tube}

In a high-pressure NMR tube with a Teflon valve, $10 \mathrm{mg}(19 \mu \mathrm{mol})$ of the substrate was dissolved along with $2 \mathrm{mg}(2.5 \mu \mathrm{mol})$ of the Grubbs-Hoveyda catalyst AquaMet (Sigma-Aldrich, catalogue 
number 901759$)$ in $1.0 \mathrm{~mL}$ D2O/THF-d8 (1:1). A dose of $5 \mu \mathrm{L}$ of $\mathrm{DCl}(36 \%$ in D2O) was added to the mixture to ensure acidic $\mathrm{pH}$. The tube was pressurized with ethylene to 4 bar after three cycles of freeze-pump-thaw. The reaction was monitored by ${ }^{1} \mathrm{HNMR}$ spectroscopy over time. Upon completion of the reaction, the mixture was extracted with Et2O and analyzed by GC MS afterwards.

\section{Conclusions}

We have shown the potential of combined bio- and chemical synthesis pathways for the production of valuable compounds. This unique alliance allows the combination of highly selective biocatalytic transformations with chemical high conversion reactions. Since 1-octene is usually obtained from petroleum we here present a synthesis route completely based on renewable resources.

Furthermore, this study sheds light on the molecular structure of the important glycolipids rhamnolipids. The unsaturation in the rhamnolipids and HAAs synthesized here was shown to be incorporated in the 5-dodecenoic acid.

Supplementary Materials: The following are available online at http://www.mdpi.com/2073-4344/10/8/874/s1, Figure S1: GC-MS analysis of the ethenolysis reaction.

Author Contributions: Conceptualization, T.T., K.B. and L.M.B.; methodology, T.T., D.F.S., K.B., C.C.B. and J.O.; writing—original draft, T.T., D.F.S., K.B. and C.C.B.; writing—review \& editing, T.T., D.F.S., J.O. and L.M.B. All authors have read and agreed to the published version of the manuscript.

Funding: This work was partially funded by the Cluster of Excellence "Tailor-Made Fuels from Biomass" (TMFB), which was funded by the Excellence Initiative of the German federal and state governments to promote science and research at German universities. The DFG is acknowledged for funding throughout the IRTG "Selectivity in Chemo- and Biocatalysis" (SeleCa, IRTG 1628). The authors have received funding from the European Union's Horizon 2020 research and innovation program under grant agreement no. 633962 for the project P4SB and grant agreement no. 863922 for the project MIX-UP. The Ministry of Culture and Science financially supported parts of this study, within the framework of the NRW Strategieprojekt Bioeconomy Science Center (BioSC) (No. 313/323-400-002 13). We also acknowledge funding by the Cluster of Excellence "The Fuel Science Center Adaptive Conversion Systems for Renewable Energy and Carbon Sources", which is funded by the Excellence Initiative of the German federal and state governments to promote science and research at German universities. We gratefully acknowledge funding by the Federal Ministry of Food and Agriculture (Bundesministerium für Ernährung und Landwirtschaft (BMEL)) under the project number 22403415 (project-executing body: Fachagentur Nachwachsende Rohstoffe (FNR)).

Conflicts of Interest: The authors declare no conflict of interest. The funders had no role in the design of the study; in the collection, analyses, or interpretation of data; in the writing of the manuscript, or in the decision to publish the results.

\section{References}

1. Bugge, M.M.; Hansen, T.; Klitkou, A. What Is the Bioeconomy? A Review of the Literature. Sustainability 2016, 8, 1-22. [CrossRef]

2. Chen, Y.; Nielsen, J. Advances in metabolic pathway and strain engineering paving the way for sustainable production of chemical building blocks. Curr. Opin. Biotechnol. 2013, 24, 965-972. [CrossRef] [PubMed]

3. Soetaert, W.; Vandamme, E. The impact of industrial biotechnology. Biotechnol. J. 2006, 1, 756-769. [CrossRef] [PubMed]

4. Williams, P.A.; Murray, K. Metabolism of benzoate and the methylbenzoates by Pseudomonas putida (arvilla) mt-2: Evidence for the existence of a TOL plasmid. J. Bac. 1974, 120, 416-423. [CrossRef] [PubMed]

5. Bagdasarian, M.; Lurz, R.; Ruckert, B.; Franklin, F.C.H.; Bagdasarian, M.M.; Frey, J.; Timmis, K.N. Specific-purpose plasmid cloning vectors II. Broad host range, high copy number, RSF1010-derived vectors, and a host-vector system for gene cloning in Pseudomonas. Gene 1981, 16, 237-247. [CrossRef]

6. Loeschcke, A.; Thies, S. Pseudomonas putida-A versatile host for the production of natural products. Appl. Microbiol. Biotechnol. 2015, 99, 6197-6214. [CrossRef]

7. Wynands, B.; Lenzen, C.; Otto, M.; Koch, F.; Blank, L.M.; Wierckx, N. Metabolic engineering of Pseudomonas taiwanensis VLB120 with minimal genomic modifications for high-yield phenol production. Metab. Eng. 2018, 47, 121-133. [CrossRef] 
8. Tiso, T.; Sabelhaus, P.; Behrens, B.; Wittgens, A.; Rosenau, F.; Hayen, H.; Blank, L.M. Creating metabolic demand as an engineering strategy in Pseudomonas putida-Rhamnolipid synthesis as an example. Metab. Eng. Commun. 2016, 3, 234-244. [CrossRef]

9. Tiso, T.; Zauter, R.; Tulke, H.; Leuchtle, B.; Li, W.-J.; Behrens, B.; Wittgens, A.; Rosenau, F.; Hayen, H.; Blank, L.M. Designer rhamnolipids by reduction of congener diversity: Production and characterization. Microb. Cell Fact. 2017, 16, 225. [CrossRef]

10. Tiso, T.; Wierckx, N.J.P.; Blank, L.M. Non-pathogenic Pseudomonas as platform for industrial biocatalysis. In Industrial Biocatalysis; Grunwald, P., Ed.; Pan Stanford: Singapore, 2015; Volume 1, pp. 323-372.

11. Wittgens, A.; Tiso, T.; Arndt, T.T.; Wenk, P.; Hemmerich, J.; Müller, C.; Wichmann, R.; Küpper, B.; Zwick, M.; Wilhelm, S.; et al. Growth independent rhamnolipid production from glucose using the non-pathogenic Pseudomonas putida KT2440. Microb. Cell Fact. 2011, 10, 80. [CrossRef]

12. Lovaglio, R.B.; Dos Santos, F.J.; Jafelicci, M.J.; Contiero, J. Rhamnolipid emulsifying activity and emulsion stability: pH rules. Colloids. Surf. B. Biointerfaces 2011, 85, 301-305. [CrossRef] [PubMed]

13. Sarachat, T.; Pornsunthorntawee, O.; Chavadej, S.; Rujiravanit, R. Purification and concentration of a rhamnolipid biosurfactant produced by Pseudomonas aeruginosa SP4 using foam fractionation. Bioresour. Technol. 2010, 101, 324-330. [CrossRef] [PubMed]

14. Lang, S.; Wullbrandt, D. Rhamnose lipids-Biosynthesis, microbial production and application potential. Appl. Microbiol. Biotechnol. 1999, 51, 22-32. [CrossRef]

15. Abdel-Mawgoud, A.M.; Lépine, F.; Déziel, E. Rhamnolipids: Diversity of structures, microbial origins and roles. Appl. Microbiol. Biotechnol. 2010, 86, 1323-1336. [CrossRef] [PubMed]

16. Zähringer, U.; Rettenmaier, H.; Moll, H.; Senchenkova, S.N.; Knirel, Y.A. Structure of a new 6-deoxy-alpha-D-talan from Burkholderia (Pseudomonas) plantarii strain DSM 6535, which is different from the O-chain of the lipopolysaccharide. Carbohydr. Res. 1997, 300, 143-151. [CrossRef]

17. Jadhav, M.; Kalme, S.; Tamboli, D.; Govindwar, S. Rhamnolipid from Pseudomonas desmolyticum NCIM-2112 and its role in the degradation of Brown 3REL. J. Basic. Microbiol. 2011, 51, 1-12. [CrossRef]

18. Rezanka, T.; Siristova, L.; Sigler, K. Rhamnolipid-producing thermophilic bacteria of species Thermus and Meiothermus. Extremophiles 2011, 15, 697-709. [CrossRef]

19. Zhu, K.; Rock, C.O. RhlA converts beta-hydroxyacyl-acyl carrier protein intermediates in fatty acid synthesis to the beta-hydroxydecanoyl-beta-hydroxydecanoate component of rhamnolipids in Pseudomonas aeruginosa. J. Bac. 2008, 190, 3147-3154. [CrossRef]

20. Germer, A.; Tiso, T.; Müller, C.; Behrens, B.; Vosse, C.; Scholz, K.; Froning, M.; Hayen, H.; Blank, L.M. Exploiting the natural diversity of the acyltransferase RhlA for the synthesis of the rhamnolipid precursor 3-(3-hydroxyalkanoyloxy)alkanoic acid. Appl. Environ. Microbiol. 2020, 86, e02317-02319. [CrossRef]

21. Grubbs, R.H. Handbook of Metathesis; Wiley-VCH: Weinheim, Germany, 2003.

22. Grela, K. Olefin Metathesis: Theory and Practice; Wiley: Hoboken, NJ, USA, 2014; pp. xiii, 592.

23. Mol, J.C. Application of olefin metathesis in oleochemistry: An example of green chemistry. Green Chem. 2002, 4, 5-13. [CrossRef]

24. Thomas, R.M.; Keitz, B.K.; Champagne, T.M.; Grubbs, R.H. Highly selective ruthenium metathesis catalysts for ethenolysis. J. Am. Chem. Soc. 2011, 133, 7490-7496. [CrossRef] [PubMed]

25. Burdett, K.A.; Harris, L.D.; Margl, P.; Maughon, B.R.; Mokhtar-Zadeh, T.; Saucier, P.C.; Wasserman, E.P. Renewable Monomer Feedstocks via Olefin Metathesis: Fundamental Mechanistic Studies of Methyl Oleate Ethenolysis with the First-Generation Grubbs Catalyst. Organometallics 2004, 23, 2027-2047. [CrossRef]

26. Julis, J.; Bartlett, S.A.; Baader, S.; Beresford, N.; Routledge, E.J.; Cazin, C.S.J.; Cole-Hamilton, D.J. Selective ethenolysis and oestrogenicity of compounds from cashew nut shell liquid. Green Chem. 2014, 16, $2846-2856$. [CrossRef]

27. Herbert, M.B.; Marx, V.M.; Pederson, R.L.; Grubbs, R.H. Concise Syntheses of Insect Pheromones Using Z-Selective Cross Metathesis. Angew. Chem. Int. Ed. 2013, 52, 310-314. [CrossRef] [PubMed]

28. Marx, V.M.; Sullivan, A.H.; Melaimi, M.; Virgil, S.C.; Keitz, B.K.; Weinberger, D.S.; Bertrand, G.; Grubbs, R.H. Cyclic Alkyl Amino Carbene (CAAC) Ruthenium Complexes as Remarkably Active Catalysts for Ethenolysis. Angew. Chem. Int. Ed. 2015, 54, 1919-1923. [CrossRef] [PubMed]

29. Jenkins, R.W.; Sargeant, L.A.; Whiffin, F.M.; Santomauro, F.; Kaloudis, D.; Mozzanega, P.; Bannister, C.D.; Baena, S.; Chuck, C.J. Cross-Metathesis of Microbial Oils for the Production of Advanced Biofuels and Chemicals. ACS Sustain. Chem. Eng. 2015, 3, 1526-1535. [CrossRef] 
30. Marinescu, S.C.; Schrock, R.R.; Müller, P.; Hoveyda, A.H. Ethenolysis Reactions Catalyzed by Imido Alkylidene Monoaryloxide Monopyrrolide (MAP) Complexes of Molybdenum. J. Am. Chem. Soc. 2009, 131, 10840-10841. [CrossRef]

31. Patel, J.; Elaridi, J.; Jackson, W.R.; Robinson, A.J.; Serelis, A.K.; Such, C. Cross-metathesis of unsaturated natural oils with 2-butene. High conversion and productive catalyst turnovers. Chem. Commun. (Cambridge, U.K.) 2005, 10, 5546-5547. [CrossRef]

32. van der Klis, F.; Le Nôtre, J.; Blaauw, R.; van Haveren, J.; van Es, D.S. Renewable linear alpha olefins by selective ethenolysis of decarboxylated unsaturated fatty acids. Eur. J. Lipid Sci. Technol. 2012, 114, 911-918. [CrossRef]

33. Nickel, A.; Ung, T.; Mkrtumyan, G.; Uy, J.; Lee, C.W.; Stoianova, D.; Papazian, J.; Wei, W.H.; Mallari, A.; Schrodi, Y.; et al. A Highly Efficient Olefin Metathesis Process for the Synthesis of Terminal Alkenes from Fatty Acid Esters. Top. Catal. 2012, 55, 518-523. [CrossRef]

34. Zhang, J.; Song, S.; Wang, X.; Jiao, J.; Shi, M. Ruthenium-catalyzed olefin metathesis accelerated by the steric effect of the backbone substituent in cyclic (alkyl)(amino) carbenes. Chem. Commun. (Cambridge, U.K.) 2013, 49, 9491-9493. [CrossRef] [PubMed]

35. Anderson, D.R.; Ung, T.; Mkrtumyan, G.; Bertrand, G.; Grubbs, R.H.; Schrodi, Y. Kinetic selectivity of olefin metathesis catalysts bearing cyclic (alkyl)(amino)carbenes. Organometallics 2008, 27, 563-566. [CrossRef] [PubMed]

36. Spekreijse, J.; Sanders, J.P.M.; Bitter, J.H.; Scott, E.L. The Future of Ethenolysis in Biobased Chemistry. ChemSusChem 2017, 10, 470-482. [CrossRef] [PubMed]

37. Behr, A.; Toepell, S.; Harmuth, S. Cross-metathesis of methyl 10-undecenoate with dimethyl maleate: An efficient protocol with nearly quantitative yields. RSC Adv. 2014, 4, 16320-16326. [CrossRef]

38. Fang, H.; Zhao, C.; Kong, Q.; Zou, Z.; Chen, N. Comprehensive utilization and conversion of lignocellulosic biomass for the production of long chain $\alpha, \omega$-dicarboxylic acids. Energy 2016, 116, 177-189. [CrossRef]

39. Balcar, H.; Žilková, N.; Kubů, M.; Polášek, M.; Zedník, J. Metathesis of cardanol over ammonium tagged Hoveyda-Grubbs type catalyst supported on SBA-15. Catal. Today 2018, 304, 127-134. [CrossRef]

40. Butilkov, D.; Lemcoff, N.G. Jojoba oil olefin metathesis: A valuable source for bio-renewable materials. Green Chem. 2014, 16, 4728-4733. [CrossRef]

41. Ríos-Lombardía, N.; García-Álvarez, J.; González-Sabín, J. One-Pot Combination of Metal- and Bio-Catalysis in Water for the Synthesis of Chiral Molecules. Catalysts 2018, 8, 75. [CrossRef]

42. Rudroff, F.; Mihovilovic, M.D.; Gröger, H.; Snajdrova, R.; Iding, H.; Bornscheuer, U.T. Opportunities and challenges for combining chemo- and biocatalysis. Nat. Catal. 2018, 1, 12-22. [CrossRef]

43. Schmidt, S.; Castiglione, K.; Kourist, R. Overcoming the Incompatibility Challenge in Chemoenzymatic and Multi-Catalytic Cascade Reactions. Chem. Eur. J. 2018, 24, 1755-1768. [CrossRef]

44. Gröger, H.; Hummel, W. Combining the 'two worlds' of chemocatalysis and biocatalysis towards multi-step one-pot processes in aqueous media. Curr. Opin. Chem. Biol. 2014, 19, 171-179. [CrossRef]

45. Wilson, Y.M.; Dürrenberger, M.; Nogueira, E.S.; Ward, T.R. Neutralizing the Detrimental Effect of Glutathione on Precious Metal Catalysts. J. Am. Chem. Soc. 2014, 136, 8928-8932. [CrossRef]

46. Gómez Baraibar, Á.; Reichert, D.; Mügge, C.; Seger, S.; Gröger, H.; Kourist, R. A One-Pot Cascade Reaction Combining an Encapsulated Decarboxylase with a Metathesis Catalyst for the Synthesis of Bio-Based Antioxidants. Angew. Chem. Int. Ed. 2016, 55, 14823-14827. [CrossRef] [PubMed]

47. Bojarra, S.; Reichert, D.; Grote, M.; Baraibar, Á.G.; Dennig, A.; Nidetzky, B.; Mügge, C.; Kourist, R. Bio-based $\alpha, \omega$-Functionalized Hydrocarbons from Multi-step Reaction Sequences with Bio- and Metallo-catalysts Based on the Fatty Acid Decarboxylase OleTJE. ChemCatChem 2018, 10, 1192-1201. [CrossRef]

48. Jeschek, M.; Reuter, R.; Heinisch, T.; Trindler, C.; Klehr, J.; Panke, S.; Ward, T.R. Directed evolution of artificial metalloenzymes for in vivo metathesis. Nature 2016, 537, 661-665. [CrossRef] [PubMed]

49. Sauer, D.F.; Gotzen, S.; Okuda, J. Metatheases: Artificial metalloproteins for olefin metathesis. Org. Biomol. Chem. 2016, 14, 9174-9183. [CrossRef] [PubMed]

50. Sauer, D.F.; Schiffels, J.; Hayashi, T.; Schwaneberg, U.; Okuda, J. Olefin metathesis catalysts embedded in beta-barrel proteins: Creating artificial metalloproteins for olefin metathesis. Beilstein J. Org. Chem. 2018, 14, 2861-2871. [CrossRef] 
51. Mertens, M.A.S.; Sauer, D.F.; Markel, U.; Schiffels, J.; Okuda, J.; Schwaneberg, U. Chemoenzymatic cascade for stilbene production from cinnamic acid catalyzed by ferulic acid decarboxylase and an artificial metathease. Catal. Sci. Tech. 2019, 9, 5572-5576. [CrossRef]

52. Sauer, D.F.; Qu, Y.; Mertens, M.A.S.; Schiffels, J.; Polen, T.; Schwaneberg, U.; Okuda, J. Biohybrid catalysts for sequential one-pot reactions based on an engineered transmembrane protein. Catal. Sci. Tech. 2019, 9, 942-946. [CrossRef]

53. Katharina, T.; Miriam, S.; Jürgen, S.; Harald, G. Combination of Olefin Metathesis and Enzymatic Ester Hydrolysis in Aqueous Media in a One-Pot Synthesis. Adv. Synth. Catal. 2011, 353, 2363-2367. [CrossRef]

54. Wu, S.; Zhou, Y.; Gerngross, D.; Jeschek, M.; Ward, T.R. Chemo-enzymatic cascades to produce cycloalkenes from bio-based resources. Nat. Commun. 2019, 10, 5060. [CrossRef] [PubMed]

55. Ríos-Lombardía, N.; Rodríguez-Álvarez, M.J.; Morís, F.; Kourist, R.; Comino, N.; López-Gallego, F.; González-Sabín, J.; García-Álvarez, J. DESign of Sustainable One-Pot Chemoenzymatic Organic Transformations in Deep Eutectic Solvents for the Synthesis of 1,2-Disubstituted Aromatic Olefins. Front. Chem. 2020, 8. [CrossRef] [PubMed]

56. Aresta, M.; Dibenedetto, A.; Dumeignil, F. Biorefinery: From Biomass to Chemicals and Fuels; [Walter] de Gruyter: Berlin, Germany, 2012.

57. Grubbs, R.H. Olefin metathesis. Tetrahedron 2004, 60, 7117-7140. [CrossRef]

58. Keim, W. Oligomerization of Ethylene to $\alpha$-Olefins: Discovery and Development of the Shell Higher Olefin Process (SHOP). Angew. Chem. Int. Ed. 2013, 52, 12492-12496. [CrossRef] [PubMed]

59. Bollmann, A.; Blann, K.; Dixon, J.T.; Hess, F.M.; Killian, E.; Maumela, H.; McGuinness, D.S.; Morgan, D.H.; Neveling, A.; Otto, S.; et al. Ethylene Tetramerization: A New Route to Produce 1-Octene in Exceptionally High Selectivities. J. Am. Chem. Soc. 2004, 126, 14712-14713. [CrossRef]

60. van Leeuwen, P.W.N.M.; Clément, N.D.; Tschan, M.J.L. New processes for the selective production of 1-octene. Coord. Chem. Rev. 2011, 255, 1499-1517. [CrossRef]

61. Vasile, C. Handbook of Polyolefins, 2nd ed.; Marcel Dekker: New York, NY, USA, 2000; pp. xiii, 1014.

62. Börner, A.; Franke, R. Hydroformylation: Fundamentals, Processes, and Applications in Organic Synthesis; Börner, A., Franke, R., Eds.; Wiley-VCH Verlag GmbH \& Co. KGaA: Weinheim, Germany, 2016; chapter 4; pp. 285-378. [CrossRef]

63. Bator, I.; Wittgens, A.; Rosenau, F.; Tiso, T.; Blank, L.M. Comparison of three xylose pathways in Pseudomonas putida KT2440 for the synthesis of valuable products. Front. Bioeng. Biotechnol. 2020, 7, 480. [CrossRef]

64. Tomasek, J.; Schatz, J. Olefin metathesis in aqueous media. Green Chem. 2013, 15, 2317-2338. [CrossRef]

65. Cronan, J.E.; Thomas, J. Bacterial fatty acid synthesis and its relationships with polyketide synthetic pathways. Method. Enzymol. 2009, 459, 395-433. [CrossRef]

66. Behrens, B.; Engelen, J.; Tiso, T.; Blank, L.M.; Hayen, H. Characterization of rhamnolipids by liquid chromatography/mass spectrometry after solid-phase extraction. Anal. Bioanal. Chem. 2016, 408, 2505-2514. [CrossRef]

67. Rendell, N.B.; Taylor, G.W.; Somerville, M.; Todd, H.; Wilson, R.; Cole, P.J. Characterisation of Pseudomonas rhamnolipids. Biochim. Biophys. Acta 1990, 1045, 189-193. [CrossRef]

68. Lebron-Paler, A. Solution and Interfacial Characterization of Rhamnolipid Biosurfactant from P. aeruginosa ATCC 9027; The University of Arizona: Tucson, AZ, USA, 2008.

69. Behrens, B.; Helmer, P.O.; Tiso, T.; Blank, L.M.; Hayen, H. Rhamnolipid biosurfactant analysis using online turbulent flow chromatography-liquid chromatography-tandem mass spectrometry. J. Chromatogr. A 2016, 1465, 90-97. [CrossRef] [PubMed]

70. Goldfine, H. Membrane Lipid Biogenesis. In Biogenesis of Fatty Acids, Lipids and Membranes; Geiger, O., Ed.; Springer Nature Switzerland AG: Berlin/Heidelberg, Germany, 2019.

71. Nelson, K.E.; Weinel, C.; Paulsen, I.T.; Dodson, R.J.; Hilbert, H.; Martins dos Santos, V.A.P.; Fouts, D.E.; Gill, S.R.; Pop, M.; Holmes, M.; et al. Complete genome sequence and comparative analysis of the metabolically versatile Pseudomonas putida KT2440. Environ. Microbiol. 2002, 4, 799-808. [CrossRef] [PubMed]

72. Köhler, K.A.K.; Ruckert, C.; Schatschneider, S.; Vorholter, F.J.; Szczepanowski, R.; Blank, L.M.; Niehaus, K.; Goesmann, A.; Puhler, A.; Kalinowski, J.; et al. Complete genome sequence of Pseudomonas sp strain VLB120 a solvent tolerant, styrene degrading bacterium, isolated from forest soil. J. Biotechnol. 2013, 168, 729-730. [CrossRef] [PubMed] 
73. Panke, S.; Witholt, B.; Schmid, A.; Wubbolts, M.G. Towards a biocatalyst for (S)-styrene oxide production: Characterization of the styrene degradation pathway of Pseudomonas sp. strain VLB120. Appl. Environ. Microbiol. 1998, 64, 2032-2043. [CrossRef]

74. Bertani, G. Studies on lysogenesis I.: The mode of phage liberation by lysogenic Escherichia coli. J. Bac. 1951, 62, 293-300. [CrossRef]

75. Silva-Rocha, R.; Martinez-Garcia, E.; Calles, B.; Chavarria, M.; Arce-Rodriguez, A.; de las Heras, A.; Paez-Espino, A.D.; Durante-Rodriguez, G.; Kim, J.; Nikel, P.I.; et al. The Standard European Vector Architecture (SEVA): A coherent platform for the analysis and deployment of complex prokaryotic phenotypes. Nucleic Acids Res. 2013, 41, D666-D675. [CrossRef]

76. Kovach, M.E.; Elzer, P.H.; Hill, D.S.; Robertson, G.T.; Farris, M.A.; Roop II, R.M.; Peterson, K.M. Four new derivatives of the broad-host-range cloning vector pBBR1MCS, carrying different antibiotic-resistance cassettes. Gene 1995, 166, 175-176. [CrossRef]

77. Fulmer, G.R.; Miller, A.J.M.; Sherden, N.H.; Gottlieb, H.E.; Nudelman, A.; Stoltz, B.M.; Bercaw, J.E.; Goldberg, K.I. NMR Chemical Shifts of Trace Impurities: Common Laboratory Solvents, Organics, and Gases in Deuterated Solvents Relevant to the Organometallic Chemist. Organometallics 2010, 29, 2176-2179. [CrossRef]

78. Philippart, F.; Arlt, M.; Gotzen, S.; Tenne, S.-J.; Bocola, M.; Chen, H.-H.; Zhu, L.; Schwaneberg, U.; Okuda, J. A Hybrid Ring-Opening Metathesis Polymerization Catalyst Based on an Engineered Variant of the $\beta$-Barrel Protein FhuA. Chem. Eur. J. 2013, 19, 13865-13871. [CrossRef]

(C) 2020 by the authors. Licensee MDPI, Basel, Switzerland. This article is an open access article distributed under the terms and conditions of the Creative Commons Attribution (CC BY) license (http://creativecommons.org/licenses/by/4.0/). 